\title{
Biological evaluation of aromatic bis-sulfonamide Schiff bases as antioxidant, acetylcholinesterase and butyrylcholinesterase inhibitors
}

\author{
Nebih LOLAK ${ }^{1}$ (D), Suleyman AKOCAK ${ }^{1}$ * (D) \\ ${ }^{I}$ Adiyaman University, Faculty of Pharmacy, Department of Pharmaceutical Chemistry, 02040, Adıyaman, Türkiye
}

\begin{abstract}
Aromatic/heterocyclic Schiff bases are one of the most investigated and studied scaffold for many pharmaceutical applications. For this reason, in the current work, a series of aromatic bis-sulfonamide Schiff bases (7-15) were re-synthesized by reacting aromatic bis-aldehydes and aromatic sulfonamides in ethanol and assayed for antioxidant properties by using different bioanalytical methods such as DPPH free radical scavenging assay, ABTS cation radical decolarization, cupric reducing antioxidant capacity (CUPRAC) and metal chelating methods. The acetylcholinesterase (AChE) and butyrylcholinesterase (BChE) inhibition profiles were also assessed. In general, the synthesized compounds showed weak antioxidant activity against all tested methods, but two compounds (12 and 15) showed good CUPRAC activity at 10, 25 and $50 \mu \mathrm{M}$ concentrations. The weak inhibition potency was obtained against AChE and moderate activity was observed against BChE enzymes at $200 \mu \mathrm{M}$.
\end{abstract}

\section{Article info \\ History:}

Received:23.07.2019

Accepted:17.04.2020

Keywords:

Sulfonamide,

Schiff base,

Antioxidant,

Anticholinesterase.

\section{Introduction}

Schiff bases $(\mathrm{R}-\mathrm{C}=\mathrm{N}-\mathrm{R})$ are one of the most versatile ligands which are synthesized from the condensation of primary amines with active carbonyl groups [1]. The imine group of the Schiff bases is an interesting core for medicinal chemistry applications. In literature, Schiff base derivatives shown to have broad biological properties such as antimicrobial, antifungal, diuretics and antitumor activities [2-8]. More specifically, aromatic/heterocyclic mono and bis sulfonamide Schiff bases were investigated as carbonic anhydrase inhibitors (CAIs) [9-12] and histamine Schiff bases as carbonic anhydrase activators (CAAs) by several groups and us [13-15]. Although mono type of sulfonamide Schiff bases was extensively investigated for many different biological applications, bis type of sulfonamide Schiff base derivatives was not yet investigated, the best of our knowledge, as an antioxidant and cholinesterase inhibitors.

More recently, our group showed the efficient carbonic anhydrase inhibition profile on aromatic bissulfonamide Schiff base derivatives [9]. The nanomolar potency was obtained against human carbonic anhydrase IX and XII (hCA IX and XII), which are tumor-overexpressed membrane-bound isozymes of carbonic anhydrase enzyme [9]. Since the potent inhibition profile of these compounds, in the present study, prompted by these potent biological activities, we re-synthesized and assessed these aromatic bis-sulfonamide Schiff bases as antioxidant and cholinesterase (AChE and $\mathrm{BChE}$ ) inhibitors.

\section{Material and Methods}

\subsection{Chemistry}

General synthetic route for the preparation of aromatic bis-sulfonamide Schiff bases (7-15) were depicted in Figure 1. These compounds were synthesized and characterized previously by us as an efficient carbonic anhydrase inhibitors [9]. As a general procedure for the synthesis of aromatic bis-sulfonamide Schiff bases, the aromatic sulfonamides were conjugated with aromatic bis-aldehydes in ethanol in the presence of a few drops of formic acid as a catalyst and then refluxed. The obtained compounds were washed with ice-cold methanol/ethanol and collected by filtration. The final compounds (7-15) were dried under vacuum and characterized by physicochemical and spectroscopic methods as previously described by us [9]. 


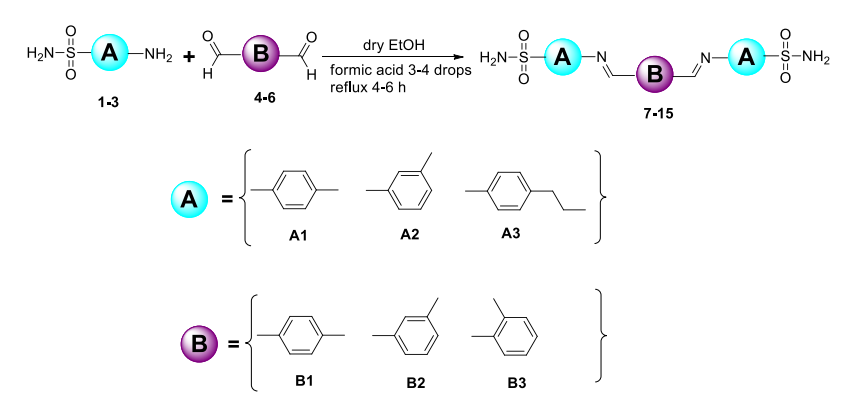

Figure 1. General synthetic route for the synthesis of bissulfonamide Schiff bases (7-15) [9].

\subsection{Determination of antioxidant and anticholinesterase activity of bis-sulfonamide schiff bases (7-15)}

\subsubsection{DPPH radical scavenging ability}

The DPPH (2,2-diphenyl-1-picrylhydrazyl) radical scavenging activity of the synthesized compounds was determined by spectrophotometric method based on the reduction of an ethanol solution of DPPH [16]. 2, $5,10,20 \mu \mathrm{L}$ of $1 \mathrm{mM}$ stock solution of each compound was completed to $40 \mu \mathrm{L}$ with the DMSO and mixed with $160 \mu \mathrm{L}$ of $0.1 \mathrm{mM}$ of DPPH free radical solution. The mixture was led to stand for $30 \mathrm{~min}$ in the dark and the absorbance was then measured at $517 \mathrm{~nm}$ against a blank. Inhibition of free radical, DPPH, in percent (I $\%$ ) was calculated according to the formula:

$\mathrm{I} \%=\left(\mathrm{A}_{\text {control }}-\mathrm{A}_{\text {sample }}\right) / \mathrm{A}_{\text {control }} \times 100$;

where $\mathrm{A}_{\text {control }}$ is the absorbance of the control reaction (containing all reagents except for the tested compounds), and $\mathrm{A}_{\text {sample }}$ is the absorbance of the test compounds. Tests were carried out in triplicate. BHA, BHT and $\alpha$-Toc were used as positive control.

\subsubsection{ABTS cation radical decolorization}

The percent inhibition of decolorization of ABTS (2,2-azino-bis(3-ethylbenzothiazoline-6-sulfonic acid)) cation radical is obtained as a function of time and concentration, and evaluated by comparison with the BHT, BHA and $\alpha$-Toc compounds used as standard $[17,18]$. The tested compounds at different concentrations are added to each well and $160 \mu \mathrm{L}$ of 7 $\mathrm{mM}$ ABTS solution is added. After $6 \mathrm{~min}$ at room temperature, the absorbances were measured at 734 $\mathrm{nm}$. ABTS cation radical decolorization activities were determined by using the equation below:

\%Inhibition $=\left(\mathrm{A}_{\text {control }}-\mathrm{A}_{\text {sample }}\right) / \mathrm{A}_{\text {control }} \mathrm{x} 100$ where $\mathrm{A}$ is the absorbance. Tests were carried out in triplicate. BHA, BHT and $\alpha$-Toc were used as positive control.

\subsubsection{Metal Chelate}

The chelating ability of synthesized compounds was examined according to the method of Dinis et al. [19]. The tested compounds at different concentrations were added to each well and $4 \mu \mathrm{L}$ of $2 \mathrm{mM}$ ferrous (II) chloride was added. Then $8 \mu \mathrm{L}$ of $5 \mathrm{mM}$ ferrozine was added and the reaction was started. After $10 \mathrm{~min}$ at room temperature, the absorbance was measured at 562 $\mathrm{nm}$ against blank. The results were expressed as percentage of inhibition of the ferrozine- $\mathrm{Fe}^{2+}$ complex formation. The percentage inhibition of the ferrozine $\mathrm{Fe}^{2+}$ complex formation was calculated using the formula given below:

Chelating ability $(\%)=\left(\mathrm{A}_{\text {control }}-\mathrm{A}_{\text {sample }}\right) / \mathrm{A}_{\text {control }} \times 100$

where A is the absorbance. Tests were carried out in triplicate. EDTA was used as a positive control.

\subsubsection{Cupric reducing antioxidant capacity (CUPRAC) method}

CUPRAC method comprises the reduction of $\mathrm{Cu}(\mathrm{II})$ Neocuproine into its colored form $\mathrm{Cu}(\mathrm{I})$-Neocuproine chelate in the presence of antioxidant compounds [20, 21]. The tested compounds at different concentrations were added to each well and $61 \mu \mathrm{L}$ of $\mathrm{CuCl}_{2}$, Neocuproine and $\mathrm{NH}_{4} \mathrm{OAc}$ solutions were added. After 1 hour at room temperature, the absorbance was measured at $450 \mathrm{~nm}$. The absorbance values were compared with the standard molecules BHA, BHT and $\alpha$-Toc. Each of samples was applied three times.

2.2.5. Anticholinesterase activity of the bissulfonamide Schiff bases

The inhibitory effect of bis-sulfonamide Schiff base derivatives (7-15) on $\mathrm{AChE}$ and $\mathrm{BChE}$ activities was determined according to the slightly modified spectrophotometric method of Ellman et al. [22]. All compounds were dissolved in DMSO to prepare stock solutions at $4 \mathrm{mM}$ concentration. Aliquots of $150 \mu \mathrm{L}$ of $100 \mathrm{mM}$ sodium phosphate buffer ( $\mathrm{pH} 8.0), 10 \mu \mathrm{L}$ of sample solution and $20 \mu \mathrm{L} \mathrm{AChE} \mathrm{(or} \mathrm{BChE)}$ solution were mixed and incubated for $15 \mathrm{~min}$ at $25^{\circ} \mathrm{C}$, and DTNB (5,5'-Dithio-bis(2-nitro-benzoic)acid) (10 $\mu \mathrm{L})$ is added. The reaction was then initiated by the addition of acetylthiocholine iodide (or butyrylthiocholine iodide) $(10 \mu \mathrm{L})$. The final 
concentration of the tested compounds' solution was $200 \mu \mathrm{M}$.

$\%$ Inhibition $=\left(\mathrm{A}_{\text {control }}-\mathrm{A}_{\text {sample }}\right) / \mathrm{A}_{\text {control }} \times 100$

where A is the absorbance. Tests were carried out in triplicate. Galantamine was used as positive control.

$\mathrm{IC}_{50}$ values were calculated from the equation of the curve obtained from the concentration-inhibition graph. The value of $\mathrm{IC}_{50}$ is the value found when we write fifty instead of inhibition in the equation of the obtained curve.

\subsection{Statistical analysis}

The results of the antioxidant and anticholinesterase activity assays are expressed as the mean \pm SD of three parallel measurements. The statistical significance was estimated using a Student's t-test, where p-values < 0.05 were considered significant.

\section{Results and Discussion}

In the current study, we report the antioxidant, acetylcholinesterase and butyrylcholinesterase inhibition activities of a series of bis-sulfonamide Schiff base derivatives (7-15). These compounds were re-synthesized as described in our previously published work. In the present study, the main idea was to assess antioxidant and cholinesterase activities of these potent carbonic anhydrase inhibitors.

Schiff bases and their metal complexes were extensively studied as a potential antioxidant regeants [23, 24]. Specifically, a histamine Schiff bases were recently evaulated as an antioxidant and cholineterase inhibitors by us [20]. Among the series, most of the compounds showed moderate antioxidant activity with $\mathrm{IC}_{50}$ values ranging from 249.63 to $945.23 \mu \mathrm{M}$ for DPPH activity, from 89.18 to $868.89 \mu \mathrm{M}$ for ABTS activity, and from 70.34 to $296.25 \mu \mathrm{M}$ for metal chelating activity. Another study from the Khan et al. [25], demonstrated the $\mathrm{IC}_{50}$ values within the range of 15.16-48.26 $\mu \mathrm{M}$ for in vitro free radical scavenging activity by using Schiff bases of 4-amino-1,5dimethyl-2-phenylpyrazolones. Aslam et al. [26], showed also DPPH antioxidant activity of Schiff bases that synthesized from the condensation of 2aminophenol and various chloro- and nitrobenzaldehydes. The good antioxidant activity was observed from these compounds with $\mathrm{IC}_{50}$ values ranging from 17.2 to $33.1 \mu \mathrm{M}$ having much better potential when compared with the standard BHA [26].
The antioxidant capacities of synthesized bissulfonamide Schiff base derivatives (7-15) are determined by using four different antioxidant methods, including DPPH free radical scavenging, ABTS cation radical decolorization, cupric reducing (CUPRAC) and metal chelating methods. Acetylcholinesterase and butyrylcholinesterase inhibition activities were also investigated.

The results revealed that bis-sulfonamide Schiff base derivatives (7-15) showed no significant activity in case of DPPH free radical scavenging method with $\mathrm{IC}_{50}$ values of $>1000 \mu \mathrm{M}$. In the present work, all compounds were less active than the standard BHA $(61.72 \mu \mathrm{M})$, BHT $(232.11 \mu \mathrm{M})$, and $\alpha$-Toc $(56.86 \mu \mathrm{M})$ (Table 1) in case of DPPH free radical scavenging method. The ABTS cation radical scavenging activities of synthesized compounds was assayed and compared with BHT, BHA, and $\alpha$-Toc used as standards and $\mathrm{IC}_{50}$ values of compounds were summarized in Table 1 . All compounds showed weak activity with $\mathrm{IC}_{50}$ values of $<1000 \mu \mathrm{M}$, except the compounds 12 (A2B3) and 13 (A3B1) displayed moderate activity with $\mathrm{IC}_{50}$ values of 964.82 and $355.77 \mu \mathrm{M}$, respectively (Table 1 ).

The metal chelating effect of the bis-sulfonamide Schiff base derivatives on iron (II) ions was presented in Table 1 and compared with standard EDTA. It was considered that compounds 13 (A3B1) and 15 (A3B3) were the most active compounds with $\mathrm{IC}_{50}$ values of 92.31 and $70.32 \mu \mathrm{M}$, respectively. Interestingly, both of these compounds have 4-(2-aminoethyl) benzenesulfonamide moiety.These compounds showed close chelating activity to standard EDTA $\left(\mathrm{IC}_{50}=52.35 \mu \mathrm{M}\right)$. The remaining compounds showed moderate chelating activity with $\mathrm{IC}_{50}$ values ranging from 101.43 to $268.56 \mu \mathrm{M}$, except the compound 12 (A2B3), which displayed no chelating activity with $\mathrm{IC}_{50}$ value of $>1000 \mu \mathrm{M}$.

The cupric reducing antioxidant capacity (CUPRAC) method was also applied to identify the antioxidant activity of the prepared bis-sulfonamide Schiff base derivatives (7-15). As expected, the activity of the compounds increased with increasing concentration $(10$ to $100 \mu \mathrm{M})$ as shown in Table 2 . The results of the CUPRAC test of the synthesized compounds at 10, 25, 50 and $100 \mu \mathrm{M}$ were compared with standards BHT, BHA and $\alpha$-Toc. In the current study, the compounds 12 (A2B3) and 15 (A3B3) showed a better CUPRAC activity than standard $\alpha$-Toc at 10,25 and $50 \mu \mathrm{M}$. Specifically, the compound 12 had better activity at 10 $\mu \mathrm{M}$ of concentration than all three standards (BHT, BHA and $\alpha$-Toc). Interestingly, these two active compounds (12 and 15) have 1,2-disubstituted phenyl (B3) with different sulfonamides (A2 and A3). 
Table 1. DPPH radical scavenging, ABTS cation radical decolorization and metal chelating activities of aromatic bissulfonamide Schiff base derivatives (7-15) and controls BHA, BHT, $\alpha$-Toc, and EDTA.

\begin{tabular}{cccccc}
\hline & & & \multicolumn{3}{c}{$\mathrm{IC}_{50}(\mu \mathrm{M})^{\mathrm{a}}$} \\
\cline { 3 - 6 } Comp. & A & B & $\begin{array}{c}\text { DPPH Free Radical } \\
\text { Scavenging Activity }\end{array}$ & $\begin{array}{c}\text { ABTS Cation Radical } \\
\text { Scavenging Activity }\end{array}$ & $\begin{array}{c}\text { Metal Chelating } \\
\text { Activity }\end{array}$ \\
\hline 7 & A1 & B1 & $>1000$ & $>1000$ & $101.43 \pm 1.24$ \\
8 & A1 & B2 & $>1000$ & $>1000$ & $144.51 \pm 1.91$ \\
9 & A1 & B3 & $>1000$ & $>1000$ & $120.55 \pm 0.06$ \\
10 & A2 & B1 & $>1000$ & $>1000$ & $268.56 \pm 1.04$ \\
11 & A2 & B2 & $>1000$ & $>1000$ & $109.90 \pm 1.14$ \\
12 & A2 & B3 & $>1000$ & $964.82 \pm 0.94$ & $>1000$ \\
13 & A3 & B1 & $>1000$ & $355.77 \pm 0.50$ & $92.31 \pm 0.26$ \\
14 & A3 & B2 & $>1000$ & $>1000$ & $181.34 \pm 1.78$ \\
15 & A3 & B3 & $>1000$ & $>1000$ & $70.32 \pm 2.26$ \\
BHA $^{\text {b }}$ & -- & -- & $61.72 \pm 0.85$ & $45.40 \pm 1.08$ & - \\
BHT $^{\mathrm{b}}$ & -- & -- & $232.11 \pm 3.01$ & $26.54 \pm 0.18$ & - \\
$\alpha-$ TOC $^{\mathrm{b}}$ & -- & -- & $56.86 \pm 0.77$ & $34.12 \pm 0.41$ & $52.35 \pm 1.15$ \\
EDTA $^{\mathrm{b}}$ & -- & -- & - & - & \\
\hline
\end{tabular}

${ }^{\mathrm{a}} \mathrm{IC}_{50}$ values represent the means (standard deviation of three parallel measurements $(\mathrm{p}<0.05)$.

${ }^{\mathrm{b}}$ Reference compounds.

Table 2. Absorbance values for the cupric ion reducing antioxidant capacity (CUPRAC), of the aromatic bis-sulfonamide Schiff base derivatives (7-15) and controls BHA, BHT, and $\alpha$-Toc.

\begin{tabular}{ccccccc}
\hline Comp. & \multicolumn{5}{c}{ Absorbance Values $^{\mathrm{a}}$} \\
\cline { 2 - 7 } & A & B & $10 \mu \mathrm{M}$ & $25 \mu \mathrm{M}$ & $50 \mu \mathrm{M}$ & $100 \mu \mathrm{M}$ \\
\hline 7 & A1 & B1 & $0.076 \pm 0.001$ & $0.083 \pm 0.005$ & $0.090 \pm 0.012$ & $0.097 \pm 0.002$ \\
8 & A1 & B2 & $0.086 \pm 0.002$ & $0.177 \pm 0.002$ & $0.288 \pm 0.001$ & $0.398 \pm 0.005$ \\
9 & A1 & B3 & $0.085 \pm 0.002$ & $0.090 \pm 0.004$ & $0.117 \pm 0.004$ & $0.222 \pm 0.004$ \\
10 & A2 & B1 & $0.084 \pm 0.004$ & $0.085 \pm 0.003$ & $0.087 \pm 0.003$ & $0.101 \pm 0.003$ \\
11 & A2 & B2 & $0.088 \pm 0.002$ & $0.178 \pm 0.003$ & $0.281 \pm 0.001$ & $0.399 \pm 0.005$ \\
12 & A2 & B3 & $0.277 \pm 0.001$ & $0.391 \pm 0.005$ & $0.494 \pm 0.003$ & $0.512 \pm 0.002$ \\
13 & A3 & B1 & $0.121 \pm 0.085$ & $0.277 \pm 0.002$ & $0.383 \pm 0.001$ & $0.395 \pm 0.006$ \\
14 & A3 & B2 & $0.082 \pm 0.003$ & $0.077 \pm 0.002$ & $0.084 \pm 0.002$ & $0.099 \pm 0.003$ \\
15 & A3 & B3 & $0.377 \pm 0.004$ & $0.479 \pm 0.000$ & $0.583 \pm 0.002$ & $0.791 \pm 0.003$ \\
BHA $^{\text {b }}$ & -- & -- & $0.288 \pm 0.015$ & $0.572 \pm 0.046$ & $1.026 \pm 0.013$ & $1.984 \pm 0.035$ \\
BHT $^{\text {b }}$ & -- & -- & $0.303 \pm 0.010$ & $0.610 \pm 0.010$ & $1.167 \pm 0.024$ & $2.000 \pm 0.173$ \\
$\alpha-$ TOC $^{\mathrm{b}}$ & -- & -- & $0.179 \pm 0.001$ & $0.296 \pm 0.012$ & $0.482 \pm 0.017$ & $0.912 \pm 0.065$ \\
\hline
\end{tabular}

${ }^{a}$ Values expressed are means \pm SD of three parallel absorbance measurements $(\mathrm{p}<0.05)$

${ }^{\mathrm{b}}$ Reference compounds

In this study, a series of aromatic bis-sulfonamide Schiff bases were assessed against cholinesterase (AChE and BChE) enzyme. None of the compounds from the series showed better activity than standard drug galantamine (Table 3). Specifically, only three compounds 13, 14 and 15, showed some activity against AChE with \% inhibitions about 16.19, 5.42 and 24.00, respectively. Interestingly, these three compounds have A3 (4-(2aminoethyl)benzenesulfonamide) substitution with different linker types (B1, B2 and B3). Slightly better activity was observed against $\mathrm{BChE}$, which all compounds had some activity with \% inhibitions ranging from 5.44 to 26.19 at $200 \mu \mathrm{M}$. Specifically, compounds 7, 8 and 15 showed moderate activity against BChE with \% inhibition rates 26.19, 24.40 and 21.17, respectively. The remaining compounds showed weak inhibition activity against BChE enzyme with \% inhibition values ranging from 5.44 to 13.69 depending on the nature of the compounds (Table 3 ). 
Table 3. Anticholinesterase activity of the aromatic bis-sulfonamide Schiff base derivatives (7-15) at $200 \mu \mathrm{M}$ and standard drug galantamine.

\begin{tabular}{ccccc}
\hline Comp. & A & B & AChE $($ Inhibition \%) & BChE $\left(\right.$ Inhibition \%) $^{\mathrm{a}}$ \\
\hline 7 & A1 & B1 & NA & $26.19 \pm 0.33$ \\
8 & A1 & B2 & NA & $24.40 \pm 0.25$ \\
9 & A1 & B3 & NA & $6.97 \pm 0.24$ \\
10 & A2 & B1 & NA & $7.40 \pm 0.32$ \\
11 & A2 & B2 & NA & $6.12 \pm 0.20$ \\
12 & A2 & B3 & NA & $10.20 \pm 0.72$ \\
13 & A3 & B1 & $16.19 \pm 0.57$ & $13.69 \pm 0.37$ \\
14 & A3 & B2 & $5.42 \pm 0.79$ & $5.44 \pm 0.92$ \\
15 & A3 & B3 & $24.00 \pm 0.78$ & $21.17 \pm 0.36$ \\
Galantamine & -- & -- & $84.20 \pm 0.74$ & $87.86 \pm 0.24$ \\
\hline
\end{tabular}

${ }^{\text {a } 200 \mu \mathrm{M}}$

${ }^{\mathrm{b}}$ Standart madde

NA: Not Active

\section{Conclusions}

In the current study, a series of aromatic bissulfonamide Schiff bases (7-15) were re-synthesized from the condensation reaction of aromatic sulfonamides (A1, A2, and A3) and aromatic bisaldehydes (B1, B2 and B3). The antioxidant properties of the bis-sulfonamide Schiff base derivatives were investigated by DPPH free radical scavenging assay, ABTS cation decolarization, cupric reducing antioxidant capacity (CUPRAC) and metal chelating methods. The acetylcholinesterase (AChE) and butyrylcholinesterase (BChE) inhibition profiles were also determined. In general, weak DPPH, ABTS and metal chelating activity were observed. On the other hand, two compounds (12 and 15) showed good CUPRAC activity at 10,25 and $50 \mu \mathrm{M}$ concentrations. Some of the compounds did not show any activity against AChE (compounds 7-12). In general, a weak to moderate activity were obtained against $\mathrm{AChE}$ and BChE enzymes with \% inhibition values ranging from 5.42 to 26.9 at $200 \mu \mathrm{M}$ concentration.

\section{Acknowledgment}

This work was partially funded by The Scientific and Technological Research Council of Turkey (TUBITAK) with Grant nos. 215Z484, 315S103, and 216 S 907.

\section{Conflicts of interest}

The authors state that did not have conflict of interests

\section{References}

[1] Rani, A., Kumar, M., Khare, R., Tuli, H.S., Schiff bases as an antimicrobial agents: A review, J. Biol. Chem. Sci., 2 (2015), 62-91.

[2] Sridhar, S.K., Saravanan, M., Ramesh, A., Synthesis and antibacterial screening of hydrazones, Schiff and Mannich bases of isatin derivatives, Eur. J. Med. Chem. 36 (2001), 615625.

[3] Panneerselvam, P., Nair, R.R., Vijayalakshmi, G., Subramanian, E.H., Sridhar, S.K., Synthesis of Schiff bases of 4-(4-aminophenyl)morpholine as potential antimicrobial agents, Eur. J. Med. Chem., 40 (2005), 225-229.

[4] Lam, P.L., Lee, K.K.H., Kok, S.H.L., Gambari, R., Lam, K.H., Ho, C.L., Ma, X., Lo, Y.H., Wong, W.Y., Dong, Q.C., Bian, Z.X., Chui, C.H., Antifungal study of substituted 4pyridylmethylene-4'-aniline Schiff bases, $R S C$ Adv., 106 (2016), 104575-104581.

[5] Nizami, G., Sayyed, R., Antimicrobial, electrochemical and thermodynamic studies of Schiff base complexes and their potential as anticarcinogenic and antitumor agents: A review, IOSR J. Appl.Chem., 10 (2017), 40-51.

[6] Raquel, S.A., Pessoa, C., Lourenco, M.C.S., de Souza, V.N.M., Lessa, A.J., Synthesis, Antitubercular and Anticancer activities of pnitrophenylethylenediamine derived Schiff bases, Med. Chem. 13 (2017), 391-397.

[7] Dhar, D.N., Taploo, C.L., Schiff bases and their applications, J. Sci. Ind. Res. 41 (1982), 501506.

[8] Gupta, S.D., Revathi, B., Mazaira, G.I., Galigniana, M.D., Subrahmanyam, C.V.S., 
Gowrishankar, N.L., Raghavendra, N.M., 2,4dihydroxy benzaldehyde derived Schiff bases as small molecule Hsp90 inhibitors: Rational identification of a new anticancer lead. Bioorg. Chem., 59 (2014), 97-105.

[9] Akocak, S., Lolak, N., Nocentini, A., Karakoc, G., Tufan, A., Supuran, C.T., Synthesis and biological evaluation of novel aromatic and heterocyclic bis-sulfonamide Schiff bases as carbonic anhydrase I, II, VII and IX inhibitors, Bioorg. Med. Chem., 25 (2017), 3093-3097.

[10] Durgun, M., Turkmen, H., Ceruso, M., Supuran, C.T., Synthesis of 4-sulfamoylphenylbenzylamine derivatives with inhibitory activity against human carbonic anhaydrase isoforms I, II, IX and XII, Bioorg. Med. Chem., 24 (2016), 982-988.

[11] Sarikaya, B., Ceruso, M., Carta, F., Supuran, C.T., Inhibition of carbonic anhydrase isoforms I, II, IX ad XII with novel Schiff bases: Identification of selective inhibitors for the tumor-associated isoforms over the cytosolic ones, Bioorg. Med. Chem., 22 (2014), 58835890.

[12] Durgun M, Turkes C, Isik M, Demir, Y., Sakli, A., Kuru, A., Guzel, A., Beydemir, S., Akocak, S., Osman, S.M., AlOthman, Z., Supuran, C.T., Synthesis, characterization, biological evaluation, and in silico studies of novel series sulfonamide derivatives. J. Enzyme Inhib. Med. Chem. $35 \quad$ (2020), doi:10.1080/14756366.2020.1746784.

[13] Akocak, S., Lolak, N., Vullo, D., Durgun, M., Supuran, C.T., Synthesis and biological evaluation of histamine Schiff bases as carbonic anhydrase I, II, IV, VII and IX activators, $J$. Enzyme Inhib. Med. Chem., 32 (2017), 13051312.

[14] Akocak, S., Lolak, N., Bua, S, Nocentini, A., Karakoc, G., Supuran, C.T., $\alpha$-Carbonic anhydrases are strongly activated by spinaceamine derivatives, Bioorg. Med. Chem., 27 (2019), 800-804.

[15] Akocak, S., Lolak, N., Bua, S, Nocentini, A., Supuran, C.T., Activation of human $\alpha$-Carbonic anhydrase isoforms I, II, IV and VII with bishistamine Schiff bases and bis-spinaceamine substituted derivatives, J. Enzyme Inhib. Med. Chem., 34 (2019), 1193-1198.

[16] Blois, M.S., Antioxidant determinations by the use of a stable free radical, Nature, 181 (1958), 1199-1200.

[17] Pellegrini, R.R.N., Proteggente, A., Pannala, A., Yang, M., Rice-Evans, C., Antioxidant activity applying an improved ABTS radical cation decolorization assay, Free Rad. Bio. Med., 26 (1999), 1231-1237.

[18] Akocak, S., Boga, M., Lolak, N., Tuneg, M., Sanku, R.K.K.. Design, synthesis and biological evaluatuon of 1,3-diaryltriazene-substituted sulfonamides as antioxidant, acetylcholinesterase and butyrylcholinesterase inhibitors, J. Turk Chem. Soc. Sec. A: Chem., 6 (2019), 63-70.

[19] Dinis, T.C.P., Maderia, V.M.C., Almedia, L.M.., Action of phenolic derivatives (acetoaminophen, salycilate and 5aminosalycilate) as inhibitors of membrane lipid preoxidation and as peroxyl radical scavengers, Arch. Biochem. Biophy., 315 (1994), 161-169.

[20] Akocak, S., Lolak, N., Tuneg, M., Boga, M., Antioxidant, acetylcholinesterase and butyrylcholinesterase inhibition profiles of histamine Schiff bases, J. Turk Chem. Soc. Sec. A: Chem., 6 (2019) 157-164.

[21] Apak, R., Guclu, K., Ozyurek, M., Karademir, S.E.. Novel total antioxidant capacity index for dietary polyphenols and vitamine $\mathrm{C}$ and $\mathrm{E}$, using their cupric ion reducing capability in the presence of neocuproine: CUPRAC Method, $J$. Agric. Food Chem., 52 (2004), 7970-7981.

[22] Ellman, G.L., Courtney, K.D., Andres, V., Featherstone, R.M., A new and rapid colorimetric determination of acetylcholinesterase activity, Biochem. Pharmacol., 7 (1961), 88-95.

[23] Mohapatra, R.K., Das, P.K, Pradhan, M.K., Maihub, A.A., El-ajaily, M.M., Biological aspects of Schiff base-metal complexes derived from benzaldehydes: an overview, J. Iran. Chem. Soc. 15 (2018), 2193-2227.

[24] Al Zoubi, W., Al-Hamdani, A.A.S., Kaseem, M., Synthesis and antioxidant activities of Schiff bases and their complexes: a review, Appl. Organometal. Chem., 30 (2016), 810-817.

[25] Khan, M., Khan, M., Taha, M., Salar, U., Hameed, A., Ismail, N.H., Jamil, W., Saad, S.M., Perveen, S., Kashif, S.M., Synthesis of 4amino-1,5-dimethyl-2-phenylpyrazolone derivatives and their antioxidant activity, $J$. Chem. Soc. Pak., 37 (2015), 802-810.

[26] Aslam, M., Anis, I., Mehmood, R., Iqbal, L., Iqbal, S., Khan, I., Chishti, M.S., Perveen, S., Synthesis and biological activities of 2aminophenol-based Schiff bases and their structure-activity relationship, Med. Chem. Res., 25 (2016), 109-115 